\title{
O MÉTODO DIALÉTICO DE HEGEL
}

Konrad Utz ${ }^{*}$

SÍNTESE - A questão do método na Ciência da Lógica (CL) é uma das mais controvertidas na discussão da filosofia de Hegel. O artigo defende a opinião de que o "método absoluto" de fato apresenta uma estrutura formal definida e distinta que seja o princípio geral de todo o desenvolvimento do sistema hegeliano (maduro). Defende essa interpretação contra mal-entendimentos, sobretudo contra aquele que um tal método geral tornaria a CL num formalismo vazio. O método hegeliano é apresentado como método do determinar, sendo que a CL, fundamentalmente $e$ originariamente, não e outra coisa que uma teoria de determinações aprióricas do pensar, i.é, de categorias, regras e formas lógicas. O artigo argumenta em favor da pretensão à universalidade e incondicionalidade que Hegel atribui a seu método. Quer mostrar que é exatamente essa incondicionalidade do método, e nada mas, que sustenta a necessidade e a imanência do proceder do pensar puro e, com isso, sustenta toda a pretensão à "ciência absoluta" e ao "idealismo absoluto" hegeliano. No final, porém, o texto oferece uma crítica interna a este método, que modifica decisivamente a pretensão de Hegel, embora não a destrua fundamentalmente. É que o próprio método contém um momento de indeterminação ou contingência. Essa crítica conduz ao conceito do "acaso" como princípio originário e intransponível de toda dialética e, com isso, de todo determinar-se. Determinação se realiza no acaso da dialética. $\mathrm{O}$ acaso dialético e o princípio de toda realidade.

PALAVRAS-CHAVE - Hegel. Método. Ciência da Lógica.
ABSTRACT - The question of the Method in the Science of Logic (SL) is among the most controversially debated in the discussions on Hegel. This article defends the view that there actually is a definite and distinct formal structure underlying the whole development of Hegel's (mature) system which he himself presents as the "Absolute Method". This interpretation is defended against misunderstandings, especially against the opinion that such a method should turn the SL into a empty formalism. Hegel's Method is explained as method of determining, the SL being primarily and fundamentally nothing else but a theory of the aprioric determinations of thinking, i.e. of categories, logical rules and forms. The article arguments in favor of the universality and unconditionality which Hegel claims for his Method. It tries to show that it is exactly this unconditionality of the Method, and nothing else, which supports the necessity and immanence of "pure thinking" and consequently supports Hegel's claim to "absolute science" and "absolute idealism". Finally, however, the article offers a critique of this Method, which modifies it fundamentally without destroying it totally. It is argued that there is a moment of indeterminacy or of contingency within the very Method of determining. This critique will lead to the concept of "accident" or "chance event" as original principle of all dialectics and, with this, of all determining.

KEY WORDS - Hegel. Method. Science of Logic.

Doutor. Professor. Universidade de Tübingen (Alemanha).

\begin{tabular}{|l|l|l|l|l|l|}
\hline VERITAS & Porto Alegre & v. 50 & n. 1 & Março 2005 & p. 165-185 \\
\hline
\end{tabular}


Pretendo explicitar no presente artigo o método hegeliano como um método do determinar ${ }^{1}$, argumentando, num determinado sentido, em favor da pretensão à universalidade e incondicionalidade que Hegel lhe atribui. No final, porém, quero mostrar que o próprio método contém um momento de indeterminação ou contingência que modifica decisivamente a pretensão do autor, embora não a destrua fundamentalmente.

\section{Considerações preliminares}

A questão do método é uma das mais controvertidas na discussão da filosofia de Hegel. Por isso pretendo responder - liminarmente em uma abordagem externa - à pergunta pelo que devemos esperar do "método" hegeliano ao menos na extensão necessária para excluir os mal-entendidos mais grosseiros sobre o que o enfoque interpretativo aqui desenvolvido se propõe atingir.

O termo "método absoluto" (12/240) esconde uma pretensão dupla. A primeira diz respeito à CL, a segunda ao reconhecer e ao ser em geral. De acordo com a pretensão da CL, as duas pretensões acabam por coincidir, mas a sua separação inicial facilita o trabalho de interpretação. Por essa razão, quero restringir-me num primeiro momento ao primeiro ponto. Se a CL apresenta um método contínuo, existe algo distinto que podemos descobrir em todos os passos individuais do seu procedimento, sendo, portanto, comum a eles, embora não recaia com isso em uma generalidade que não admita mais determinações decididas - como e.g. um "movimento em geral" ou um "pensamento em geral" (cf. 21/38), pré-reflexivos. Porém, esse algo distinto não deve apenas identificar-se, mas dispor também de algum potencial explicativo, e isso num sentido eminente do termo, conforme dever-se-ia esperar.

Quero demonstrar nas explanações subseqüentes o primeiro dado, a existência de um método, uma forma ou estrutura, mais especificamente de uma estrutura de negações ou de uma estrutura da negação (o que, no entanto, não chega a surpreender muito). O segundo dado, o potencial explicativo do Método Absoluto, diz respeito à cientificidade da CL na sua totalidade, quer dizer na sua necessidade (cf. 21/8, 10, 18, 33, 38f., 12/251; Enc. (1830) § 81 nota, § 231 s.). ${ }^{2}$

Esclarecidos esses dois pontos, podemos dizer com bastante facilidade o que o método absoluto não é e não precisa ser. Em primeiro lugar e sobretudo ele não tem a função de nos "poupar" de qualquer coisa: não nos alivia do trabalho penoso de seguir no detalhe miúdo a argumentação da CL, bem como, em última instância a argumentação da ciência em sua totalidade. Correspondentemente, não

\footnotetext{
Cf. Enc. (1830) § 243; cf. também H.F. FULDA, Dialektik in Konfrontation mit Hegel, em: D. HENRICH (ed.). Hegels Wissenschaft der Logik. Formation und Rekonstruktion. Stuttgart, 1986, 328 349, 331.

Assim o método apresenta, na interpretação que quero oferecer, a sustentação e a explicação daquele "nexo necessário entre as categorias" cujo entendimento segundo E. LUFT (2001, 164 s.) ainda faltava na compreensão da dialética hegeliana.
} 
podemos esperar que o método hegeliano nos forneça um "padrão de malha", ${ }^{3}$ por qual a forma plena do todo já seja fixada em todos os seus pormenores. Esse não é o caso nos métodos de outras ciências, e não faz sentido ou é liminarmente impossível supor que o método hegeliano cumpra essa tarefa. A razão pela qual alguns acabam fazendo essa suposição reside no fato de que o método na CL deve desempenhar funções construtivas e constitutivas, não meramente instrumentais (21/8). Havendo, porém, construção, dever-se-ia pensar que o princípio de construção já contivesse, como orientação prévia, a forma final do seu resultado. A argumentação desenvolvida a seguir deverá mostrar por que esse não precisa ser o caso na CL ou por que isso pode ser correto num determinado sentido, sem com isso infirmar a execução individual. Mas em princípio a construção deve resultar, não obstante todo o rigor e a monotonia do seu método, em algo que nesse método ainda não pode ser vislumbrado. Ou, para dizê-lo em outros termos: caso quiséssemos prever já na forma do método o que dele haverá de resultar, isso nos obrigaria a executar exatamente o que o procedimento da CL representa em todos os seus passos individuais. ${ }^{4}$

Se, porém, essa característica do método deveria dar-se à maneira de um padrão de malha, o método deveria ser tão complexo como a própria CL. Mas então não se trataria mais propriamente de um método, pois o conceito deste contém a possibilidade da repetição. Se, no entanto, a repetição não deve ser trivial no caso do método absoluto, o programa deve alterar-se num certo sentido. Mas essa alteração não pode simplesmente somar-se em um lugar qualquer do procedimento da Ciência da Lógica, pois isso feriria a rigorosa imanência da mesma. Por isso a alteração deve resultar do próprio método ou, para dizê-lo logo em termos mais precisos, o próprio método deve enriquecer-se - e ele mesmo deve ser o método desse enriquecimento, pois deveríamos interessar-nos justamente em saber como esse enriquecimento se processa. E nenhuma outra instância além do método da ciência pode fornecer a sua explicação.

Por outro lado, esse enriquecimento por sua vez não pode ocorrer de modo a solapar, em princípio, a generalidade e monotonia do método. Mas como devemos imaginar um enriquecimento que efetivamente contribua com algo novo, mas por outro lado deixa a estrutura geral intocada não apenas na sua forma, mas também no tocante à sua pretensão? Em Hegel já dispomos de um modelo para tal forma de enriquecimento, a saber do conceito ou da idéia absoluta. Por um lado, estas também incluem e suspendem em si [aufheben] toda a riqueza da CL, e essa inclusão e suspensão não são triviais. Por outro lado, elas também não nos poupam o trabalho de pensar todas as singulares determinações como uma só determinação do pensamento, até chegar ao final.

Assim o termo com o qual os adversários da linha de interpretação aqui adotada tentam ridicularizar esse projeto.

Isso é o caso até no padrão de malha, pelo menos na primeira volta de aplicação do padrão, até que as instruções se repitam: as indicações "dois a direita, dois a esquerda" etc. precisam ser efetuadas - seja na realidade, seja na apresentação interna da consciência - para que o padrão, instalado nas indicações de tricotar, apareça. Isso deveria valer genericamente para o método da CL. 


\section{Pensar puro}

Antes de propor a minha leitura da apresentação do método no último capítulo da CL, talvez seja útil esclarecer como vejo as pré-condições ou, melhor, as condições da lógica hegeliana. A CL é um empreendimento do pensamento puro (21/12s). Isso é, ela é realizada somente no pensar e somente pelo pensar. Todo significado que ela possui para coisas e questões além do pensar lhe é secundário e não entra na explicação própria da lógica (21/41s). Por isso, o que a CL produz, em primeira instância, não pode ser senão algo no pensar, algo pensado: determinados pensamentos, i.é. determinações do pensar $(21 / 34,49)$. Neste sentido E. Luft está certo, quando chama a CL uma semântica ou uma metasemântica. ${ }^{5}$ Devemos apenas deixar claro que ela não é uma semântica que tenha (direta ou indiretamente, enquanto metasemântica) alguma relação com um significado. O termo semeion (signo), do qual deriva semântica, normalmente implica essa relação referencial - e ela não deve entrar aqui.

Mas "pensar puro" não só significa que se trata somente de pensar e de mais nada. Hegel exige que também não se pressuponha qualquer coisa no próprio pensar: pensamentos já formados, opiniões, lembranças, hábitos de pensar, categorias, modos de proceder etc. (cf. 21/18 s.). Hegel começa com a tabula rasa. Não pressupõe nada. Aceita como único dado a tabula: o próprio pensar - mas sem qualquer determinação $(21 / 56) .{ }^{6}$ Por isso qualquer determinação que apareça no desenvolvimento deve ser produzida pelo próprio pensamento, deve ser realizada pelo ato do pensar: como resultado do realizar-se do pensar puro - e ao mesmo tempo como explicação desse próprio pensar por si mesmo (cf. 21/7 s., 39, 61 s.). A tabula, neste caso, é dinâmica e desenvolve-se por si mesma: grafa em si mesma, para usar uma expressão do campo imagético da metáfora.

Assim na interpretação do método hegeliano não podemos recorrer a determinações já dadas ou já anteriormente evoluídas no pensar (21/61s.). Não dispomos de um fundo de conceitos, categorias e regras que só falta implementar. Neste sentido a CL não é reconstrução, mas construção e produção originária: nela o pensar puro dá conteúdo a si mesmo, não aceita nenhum conteúdo pressuposto (cf. outra vez, 21/7 s., 39, 61 s.). É claro que de um ponto de vista histórico, a CL explica o que já está dado, o que já conhecemos e já usamos: a lógica, i. é, as formas e as regras do nosso pensar. Nessa perspectiva externa a CL é recons-

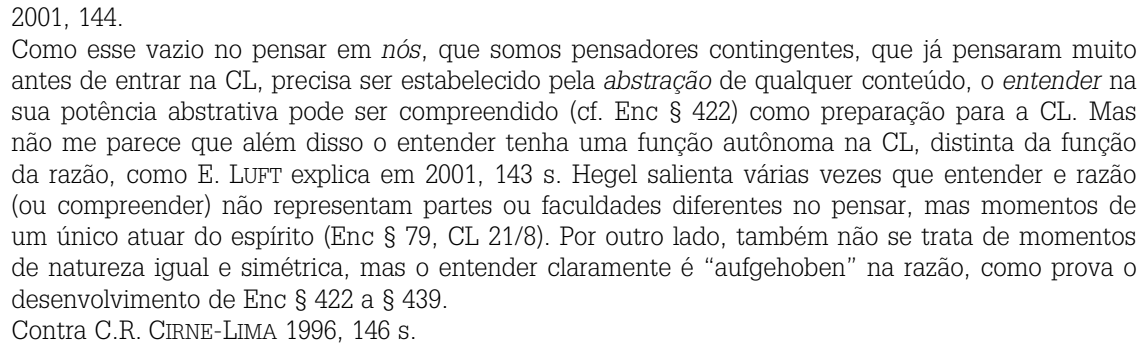

Como esse vazio no pensar em nós, que somos pensadores contingentes, que já pensaram muito antes de entrar na CL, precisa ser estabelecido pela abstração de qualquer conteúdo, o entender na sua potência abstrativa pode ser compreendido (cf. Enc § 422) como preparação para a CL. Mas não me parece que além disso o entender tenha uma função autônoma na CL, distinta da função da razão, como E. LuFT explica em 2001, 143 s. Hegel salienta várias vezes que entender e razão (ou compreender) não representam partes ou faculdades diferentes no pensar, mas momentos de um único atuar do espírito (Enc § 79, CL 21/8). Por outro lado, também não se trata de momentos de natureza igual e simétrica, mas o entender claramente é "aufgehoben" na razão, como prova o desenvolvimento de Enc $\S 422$ a § 439

Contra C.R. CIRNE-LiMA 1996, 146 s. 
trução (21/18). Mas se o ponto de partida fosse definido pelas categorias e regras lógicas enquanto historicamente dadas, a CL sempre permaneceria dependente de algo histórico, logo contingente. E se o método da lógica então consistisse em recolher determinações já dadas, a CL seria uma ciência do típo "empírico", uma "lógica natural" (como as "ciências naturais" - 21/13), pois usaria um "senso interior" para perceber alguns objetos já existentes por si mesmos no espaço lógico ou na língua, e em seguida um método apenas "analítico" para esclarecê-los (cf. ibid.). Assim a ciência da lógica não seria especulativa, logo não absoluta. Hegel desaprova a lógica tradicional exatamente por proceder de tal modo. ${ }^{8}$ Não devemos recolher categorias, mas desenvolvê-las.

Mas como é que o pensamento pode proceder sem pressupor nada? Do nada, nada vem. Aqui é mister lembrar que ainda estamos com a tabula - e agora precisamos compreender o seu aspecto positivo. Estamos com o pensar. Ou melhor: o pensar está consigo mesmo. Mas o pensar, que não pressupõe nada, não é o nãopensar, mas o pensar vazio: é o pensamento sem nenhuma determinação. Mas esse pensamento livre de qualquer conteúdo é algo distinto e inequívoco no pensar. É um pensamento, uma certa "idéia" (no sentido mais amplo da palavra), que até conhecemos do nosso pensar cotidiano e para o qual temos um nome (cf. 21/64): o "Ser". Quando pensamos o conceito que o nome "Ser" denomina, quando realizamos essa "idéia" no pensar (isso é, quando pensamos o conceito por si mesmo e não como predicado, i. é, não como ser de algo), fazemos exatamente o que o pensar puro faz no início do seu desenvolvimento: estamos pensando um pensamento sem nenhum conteúdo, nemhuma determinação específica. Pensamos nada, efetivamos um pensar vazío - uma tabula rasa.

Obviamente não queremos ficar só com isso. Queremos algo mais que esse pensamento vazío do Ser. Mas para que o pensar puro ganhe mais determinações para então concretizar-se, ele não pode buscar determinações e conceitos fora de si, mas deve gerá-los em e por si mesmo. ${ }^{9}$ Isso funciona num processo dialético de negar, de acrescentar negações e com isso determinações ao seu pensamento inicial. É isso que vamos explicar a seguir. Mas é bom esclarecer já agora do que vai tratar-se, qual será a base ou o meio do método dialético: é o pensar, o pensar puro, nada senão o pensar. A dialética determina isso, que o pensar no seu ato realiza. O pensar pensa certas determinações e estruturas de determinações. Por isso essas determinações do pensar, enquanto já conhecidas historicamente, têm

Cf. 21/35-37 (note-se a importância do método para superar esse tipo de lógica, 37)

Este processo de fato tem também o aspecto de "descobrir"; mas não de descobrir alguma coisa dada, fora do pensar puro e antes dele - nem no sentido de determinações transcendentais do seu próprio ato. Trata-se exclusivamente de um descobrir algo no seu próprio ato atual, que ainda não estava pensado explicitamente. Assim e.g. o pensar "descobre", que no ato de pensar "ser", i.é., no ato de pensar nenhuma determinação, ele na verdade já pensa um pensamento determinado, um conceito bem definido: o conceito inequivocamente definido pela indeterminidade, pela ausência de qualquer conteúdo determinado. A própria indeterminidade é uma determinação. Isso será esclarecido mais adiante. Só quero deixar claro que, com o "refletir o que já está dado", não entra nada de fora ou anteriormente dado no pensar puro, mas esse refletir se refere - e só pode referir-se ao próprio pensar puro e ao que está dado com ele (cf. 21/57s) 
nomes na língua comum (cf. 21 s.): como e.g. "ser", "nada", "essência", "necessidade", "conceito", "idéia". Para escrever o texto da CL, Hegel naturalmente usava e tinha de usar esses nomes da nossa língua historicamente desenvolvida. Mas isso não significa de maneira nenhuma que a evolução histórica da nossa língua ou dos nossos pensamentos entre na CL. ${ }^{10}$ Ao contrário, a CL abstrai totalmente desses dados históricos - abstrai de qualquer dado pressuposto - e desenvolve tudo no pensar puro, a partir do "pensamento puro", i.é. do pensamento vazio, do pensamento "ser".

\section{A apresentação do método no capítulo final da $C L^{11}$}

A apresentação do método no capitulo final da CL tem por finalidade mostrar a necessidade do procedimento da CL no geral da sua forma (cf. 12/237). Nisso há naturalmente dois pontos, que o próprio Hegel também distingue: em primeiro lugar é preciso mostrar, por que o procedimento necessariamente deve começar; em segundo lugar é preciso explicar, por que ele necessariamente deve efetuar-se pelo modo, i. é, pela forma (geral) própria da CL.

1. Se a primeira pergunta não é formulada apenas com vistas à CL, mas, seguindo a pretensão do método absoluto, com vistas a todo ser e reconhecer, é possível perguntar mais genericamente: por que Um não pode simplesmente permanecer por si só? Porque não podemos ficar simplesmente com um imediato ou com muitos imediatos? De certo modo a resposta a essa pergunta já é dada no final da CL: todos os começos, i.é. todo imediato, que apareceu no procedimento da CL, provou ser não imediato de verdade, mas mediado na sua determinidade (12/241, cf. 249 s.).

Ocorre que essa resposta ainda não satisfaz como resposta genérica, pois nada nos garante que não exista algum imediato não descoberto por Hegel, um imediato que realmente subsiste apenas por si, verdadeiramente livre de qualquer mediação. Mas essa pergunta também já é respondida, se concedemos a Hegel que só pode existir um imediato no sentido exato, conceitual do termo: o próprio ser (cf. 21/53-65). Todos os outros conceitos já contêm determinação, conseqüentemente mediação. Isso vale também para o próprio conceito do "i-mediato", formado pelo conceito do mediato acrescido da negação. Mas no ser puro manifestou-se que o mesmo nem é imediato e não pode subsistir por si, mas que ele,

${ }^{10}$ Afinal, ela é a representação de Deus antes da criação do mundo - então nada evoluído no espaço e tempo pode ser a base ou o seu material.

11 Cf. K. UTZ, Die Notwendigkeit des Zufalls. Hegels spekulative Dialektik in der „Wissenschaft der Logik" [A necessidade do acaso. A dialética especulativa de Hegel na "Ciência da Lógica"]. Paderborn, 2000, 167-177; nessa publicação, a interpretação é efetuada de um ponto de vista bem mais formal - o que explica as diferenças entre a apresentação nela e a aqui desenvolvida. Cf. também ibid. 68-112. 
justamente nessa imediatidade liminarmente reclamada, transforma-se em puro nada $(21 / 69){ }^{12}$

Ora, o começo da CL foi criticado com tamanha freqüência e sob perspectivas tão múltiplas que praticamente não podemos confiar na sua força de convencimento na questão aqui tratada. O próprio Hegel tentou enfrentar as dúvidas sobre o seu começo lógico com explicações aprofundantes, que porém não deveriam acrescentar argumentos adicionais, mas só deveriam revelar ainda mais a conversão sem mediações do ser em nada - porque toda força comprobatória residiria somente nela (cf. 21/70 s.).

Penso, contudo, ser efetivamente possível aduzir um outro argumento, de natureza genérica, para refutar a possibilidade de imediatidade pura. Ele resulta do princípio omnis determinatio est negatio de Spinoza. Toda negação é mediação. Assim tudo o que possui alguma determinação contém mediação, é algo mediato. Mas é impossível que algo seja totalmente indeterminado, livre de toda determinação - porque já a própria imediatidade é, como Hegel lembra, uma determinação. Mas esse argumento precisa recorrer, no tocante aos tópicos indicados, a duas evidências originais que ainda por cima são vinculadas sem necessidade imanente. Hegel provavelmente diria, que a evidência da virada repentina do ser em nada é mais simples e mais originária, constituindo assim a "prova" verdadeira da impossibilidade da imediatidade pura. Assim o meu argumento não reforça a evidência no mérito da própria coisa tratada. Ele só pode ser útil na discussão com os que não reconhecem plausibilidade no capítulo inicial de Hegel, mas estão dispostos a aceitar os enunciados básicos aqui empregados. ${ }^{13}$

Mas por que esse caráter mediato e essa concretude, originários de todo imediato deveriam tornar o progresso necessário? Essa necessidade resulta da decisão metodológica constitutiva da CL, de não aceitar nada de fora, mas de ater-se somente à própria "coisa" e permanecer totalmente concentrado nela. No entanto,

2 Aqui, no início da CL - como aliás também no fim - a forma do método coincide imediatamente com seu conteúdo.

13 Não concordo com CARLos CiRnE-Lima, que diz que temos que formar do mero pensamento "ser" um juízo: "o Absoluto é Ser" ou "todas as coisas são Ser", para a partir disso descobrir a insuficiéncia de tal proposição (cf. Dialética para principiantes, São Leopoldo 1996, 141-150; cf. tambem a crítica, que E. LUFT 2001, 148 lhe fez). Os argumentos contra essa posição são três: Em primeiro lugar, Hegel mesmo não descreve o procedimento dialético assim (só diz, em Enc § 85, que a primeira e última determinação de cada tríade dialética - só elas e não, como Cirne-Lima quer, também a segunda - podem ser atribuídas ao absoluto, mas logo diz que isso é totalmente supérfluo; consequentemente não pode ter nenhuma função no proceder dialético) e até explicitamente recusa tal idéia em vários lugares na Enc. (e não somente na Fen., como diz Cirne-Lima) com ênfase e insistência (cf. as citações infra). Em segundo lugar, isso exigiria, como Hegel mesmo explica, que os termos „absoluto“ ou „ todas as coisas“ já tivessem um significado (§ 31, § 50 nota, § 85). Isso seria a exigência de começar sem nada, i.é. sem nenhuma determinação (se „o Absoluto“ deve ser no início nada mais que o puro indeterminado, como Cirna-Lima explica. Em terceiro lugar, a própia forma do juízo é inadequada para exprimir a verdade (§ 31 nota), como Hegel tenta esclarecer tantas vezes (principalmente na crítica a Kant; e.g. Enc. §168). Temos de ficar (primeiramente) com as simples determinações do pensamento, que mais tarde serão explicadas como conceitos. A forma do juízo também deverá aparecer no percurso da Lógica, no seu devido lugar (e aí será provada insuficiente). Temos de esperar por isso, não adianta introduzir essa forma já antes e externamente. 
na própria coisa - e neste sentido "objetivamente" - a imediatidade e a mediatidade são inseparáveis (12/240). É claro que na reflexão podemos abstrair da mediação (resp. da imediatidade). Mas essa reflexão não surge da própria coisa e distancia-se dela. Quando, ao contrário, tomamos o que é dado por essa própria reflexão, o que é "objetivo" nela, temos exatamente o imediato, que é mediado pela abstração, conseqüentemente pela negação.

Se, porém, o imediato como início, "objetivamente" ou em si, de fato não for inicial, i. é, não for imediato, será deficiente como início (ibid.). Poder-se-ia objetar imediatamente com a seguinte pergunta: por que essa deficiência deveria estar situada na própria coisa, i. é, nesse caso no ser inicial - mesmo que este fosse uma mera determinação do pensamento, algo meramente ideal? Pois ele só é deficiente enquanto nós o tomamos como início, enquanto nós opinamos que ele deve ser imediato. Hegel talvez responderia que essa objeção não é válida no caso da CL, já porque o pensamento puro no começo dela nada quer e nada opina. O início não resulta da decisão do pensar, de perseguir um fim explicitamente definido, e.g. o fim de uma verdade sem deficiências. O início resulta somente da decisão de "querer contemplar o pensar como tal" $(21 / 56)^{14}$. Se fazemos isso, a deficiência se manifesta imediatamente na própria coisa, que com essa decisão é dada no pensar: no ser puro, que não pode ater-se a si mesmo - e não no fato de que o início não pode atender a certos critérios que lhe são exigidos.

Porém, aos que não confiam no início lógico de Hegel e suspeitam que o filósofo lhe tenha imputado, de algum modo ilegítimo, a exigência de avançar, talvez possamos responder nos seguintes termos: a exigência de estabelecer um começo, i.é. a exigência de que haja algo primacial, imediato, não é apenas uma exigência subjetiva, resultante da constituição discursiva do nosso pensar. Ela já resulta do princípio omnis determinatio est negatio, nomeadamente quando a negação é compreendida não somente como mediação em geral, mas como mediação necessariamente assimétrica. A própria negação e com isso a determinação exigem, elas mesmas, o imediato ${ }^{15}$.

É verdade que a negação assimétrica pode ser retraçada na direção da relação negativa, que é simétrica: $\mathrm{A}$ não é $\mathrm{B}$, exatamente como $\mathrm{B}$ não é $\mathrm{A}$. Mas nessa mera relação negativa a determinação se perde. Se A ou B não são, de qualquer modo, substanciosas além da relação mútua, i. é, originariamente, nãorelativamente e com isso imediatamente substanciosas com vistas à relação, então só resta deles a própria relação relativa, pois nem é possível dizer o que sejam A ou B que estão nessa relação. Assim só resta a mera, abstrata relação negativa. Admitimos que ela é em si uma determinação, mas só uma determinação singular, improdutiva, não podendo ser assim o princípio de toda determinação. A negação originária, a negação determinada e determinante precisa ser assimétrica. Essa assimetria enseja a necessidade do imediato como imediato positivo - e não ape-

14 Evidentemente o início também pode ser explicado apartir do saber absoluto da Fen. ou do „, conceito provisório" da Enc., mas aqui é decisivo, o que no mínimo basta para iniciar a CL.

15 Na negação autorelacionada ela exige sua própria imediatidade. 
nas como conceito negativo da mediação e negação. Mas se a imediatidade e o caráter inicial não são apenas uma exigência transcendental, que deve ser vinculada às nossas possibilidades subjetivas de conhecer e pensar, mas uma exigência da lógica da determinação, que afeta tudo, apenas por ser determinado, podemos compreender como a deficiência dessa imediatidade se localiza na própria coisa e não é apenas uma deficiência em relação ao nosso pensar.

A deficiência do começo na sua imediatidade - ou sua mediatidade originária que está em contradição com a exigência da imediatidade - segundo Hegel já é o proceder (12/241). Outra vez poderíamos nos ver tentados a protestar e localizar o proceder em nosso pensar e na sua discursividade. Diríamos, por exemplo: "Nós não podemos parar no primeiro, quando descobrimos, que de fato não é tão simples e universal como achamos - pelo menos quando estamos em busca da verdade. Mas disso não resulta um proceder da própria coisa. Nós reconhecemos apenas que a própria coisa é diferente do que inicialmente achamos; mas com isso reconhecemos justamente, que a própria coisa já era mediada - sem que agora, em algum modo de sucessão, ocorresse depois na própria coisa como inicialmente imediata uma mediação." Essa objeção continua plausível mesmo quando esclarecemos que "começo" e "proceder" na lógica hegeliana não designam relações temporais, mas relacionamentos assimétricos lógico-abstratos.

Mas com este esclarecimento a resposta à objeção já pode quase diretamente emendar na argumentação anterior pela deficiência na própria coisa: a explicação da assimetria do determinar exige um modo assimétrico de relacionamento no próprio explicar. Na deficiência como tal já está situado um dever, o do seu saneamento. Agora esse dever é objetivo no sentido acima explicado, pois a exigência da imediatidade estava situada, como descrito, no próprio objeto enquanto determinado. Mas a possibilidade abstrata do saneamento da deficiência ou do cumprimento do dever - que ainda não precisa significar a real possibilidade do saneamento - já implica um modo de relacionamento, que corresponde ao modo temporal de relacionamento: em primeiro lugar, a coisa deve poder estar em uma relação consigo mesma sem duplicar-se - o que é possível numa relação temporal. ${ }^{16}$ Em segundo lugar, ela deve poder, nessa relação, encontrar-se uma vez em uma condição, outra vez em outra - i. é, uma vez com, outra vez sem deficiência. Isso é possível na diferenciação de uma coisa no decorrer do tempo. ${ }^{17}$ Em terceiro lugar, porém, deve haver nessa relação uma assimetria entre os relatos, que impede que ambos os lados tenham vigência igual, i. é, o lado com e o lado sem a deficiência. Que a deficiência possa possivelmente ser remediada implica que ela nesse caso não mais exista ou apareça - ao menos enquanto não houver outra

${ }^{16}$ Se há dois exemplares de pedra em dois pontos diferentes do espaço (ao mesmo tempo), e.g. uma no Brasil e outra na Alemanha, necessariamente são duas pedras distintas. Quando há dois exemplares de pedra em dois pontos diferentes do tempo, e.g. um em 1889 e outro em 2002, pode tratarse da mesma pedra.

17 Uma maçã não pode ser verde e vermelha ao mesmo tempo; pode, porém, perfeitamente sê-lo em momentos diferentes do seu processo de seu amadurecimento. 
causa. Com essas três exigências são dadas as características formais de relacionamentos temporais, como Hegel as reclama também para o âmbito da lógica.

Naturalmente sempre é possível abstrair de uma tal assimetria formal e tornála simétrica. Em nosso exemplo isso significa: retroprojetar a mediação do proceder a partir da própria coisa na própria coisa inicialmente dada - quer dizer: situar a mediação na própria coisa já como dada no início - e subtrair a assimetria da própria coisa. ${ }^{18}$ A lógica formal procede assim, por isso ela obviamente não sabe o que fazer com a lógica de Hegel. Assim a pergunta só é: necessitamos de uma lógica assimétrica, de forma "temporal" e neste sentido "discursiva"? Ou ainda: precisamos buscar uma lógica por trás da lógica formal, que seja mais originária do que essa e da qual a lógica formal seria só uma forma de abstração? ${ }^{19}$ No meu entender, essas perguntas devem ser respondidas afirmativamente, quando procuramos pelas condições e as possibilidades do determinar ou dos conceitos. E a própria lógica formal deve supor que haja determinações ou conceitos.

Remanesce apenas a pergunta, se existe genericamente uma forma geral do determinar e da compreensão conceitual, i. é, se há algo científica ou logicamente anterior à lógica formal - ou se o que ela aceita como existente (i. é, como seu material), não é uma diversidade pura e logicamente acidental, sobre a qual nada mais podemos dizer. A pretensão de Hegel, aqui apoiada, é de que existe essa lógica "mais essencial" ou "mais originária", a lógica do conceito, a lógica do próprio logos - exatamente como lógica da determinação, que exige o conceito.

2. Uma vez estabelecido que a deficiência do imediato deve ser compreendida na sua articulação como proceder (lógico) do imediato, precisamos responder à segunda das perguntas inicialmente formuladas: como se dá esse procedimento?

Como já indicamos, o primeiro passo é a manifestação do caráter mediado do imediato (12/241). Esse caráter mediado aparece primacial ou imediatamente como diversidade, i. é, como referimento do imediato a um outro (qualquer). A determinação mínima ou formal desse outro consiste portanto em que ele seja o outro do Primeiro, o seu próprio negativo. Porém, sob as condições da Ciência da Lógica, i. é, sob as condições do pensamento puro, excluindo qualquer instância exterior, essa não é apenas a determinação mínima e formal do Segundo, mas a sua determinação completa, pois uma outra determinação que a situada na própria coisa primeiramente dada não lhe pode convir - a não ser que venha de fora, o que fica excluído. A única determinação que estava situada na coisa do imediato era o caráter mediato, ou o ser-mediado e com isso o ser-referido a algo que ele mesmo não é. Precisamente essa negatividade é aquela, que se manifestou no imediato como deficiência, ou aquela, na qual se articulou a negatio, já situada na

Hegel até explica essa figura de re-projeção: como o "pre-supor" na "Lógica da Essência".

Também seria possível formular em termos mais simples: é necessário proceder além da lógica formal e analítica até a dialética? - se, nestes dias, o próprio conceito da dialética não se tivesse tornado tão impreciso e controvertido. Quanto a essa questão cf. também C.R.V. CIRNE-LIMA, Brief über die Dialektik, in: D.WANDSCHnEIDER (ed.). Das Problem der Dialektik. Bonn, 1997, 77-89. 
determinidade do imediato. Obviamente essas já são reflexões explicativas sobre o que se executa no pensar puro. No primeiro começar se executa simplesmente a transição ou conversão do imediato em seu primeiro negativo, e.g. a transição ou conversão do ser ao nada. Somente nos procedimentos posteriores do método o próprio proceder será paulatinamente compreendido. ${ }^{20}$

Mas agora a constituição da CL não somente faz com que a negação mínima já seja a determinação plena do que segue no procedimento dialético. Não só faz com que nada lhe acresça. Também faz com que nada do que está dado seja perdido: o primeiro negativo não é vazio, mas o negativo do imediato ${ }^{21}$. A negação é negação determinada, a negação na qual o negado é conservado (12/244 f. ${ }^{22}$ - só no caso, no qual o próprio imediato é totalmente vazio, quer dizer no caso do ser puro, o negativo e o nada vazio - mas com isso já é um negativo determinado, nomeadamente o negativo determinado daquele que é determinado como completamente indeterminado e universal) ${ }^{23}$.

Como o Primeiro, imediato - já por causa da sua imediatidade - não tem forma proposicional, mas representa uma determinação simples, uma "determinação de pensar", a negação também é negação "conceitual" num sentido mais amplo do termo. Por isso, a meu ver, não é necessário derivar esse tipo de negação da lógica formal, proposicional, embora esse artigo não seja o lugar para aprofundar esse argumento.

Naturalmente ambas as condições, que nada acresça e que nada se perca, só estão garantidas no pensamento puro. Assim sendo, não devemos esperar que o método absoluto seja universal no sentido, que exatamente o que foi descrito até agora e será explanado a seguir se realize também em qualquer outro lugar, onde a determinação e o conhecimento estão em jogo. Pelo contrário, o processo neces-

20 Como o primeiro negado é uma determinação, o resultado é simplesmente a determinação negativa, o negativo dela. A negação não é a negação de um juízo, pois isso seria a negação não de uma determinação simples, mas da determinação de uma relação de determinações, i.é. entre sujeito e predicado.

${ }^{21}$ Aqui não aparece o problema de que possam existir alternativas a uma negação, de que possam existir vários negativos ao primeiro, como CIRNE-LIMA pretende em op. cit. 117 s.. O negativo simplesmente não é outra coisa que o primeiro mais a determinação da negação. Se a primeira determinação, a determinação negada, for uma determinação empírica, então poderá haver na realidade empírica várias qualidades diferentes subsumíveis à negação dessa determinação (assim como o não-branco pode ser preto ou vermelho ou outra cor) - é essa a caraterística do empírico (os exemplos de Cirne-Lima são tais determinações empíricas). Mesmo assim, a determinação negativa em si mesma fica uma única, inequívoca. Se a primeira determinação é lógica, porém, nem ocorre esse tipo de alternativas. Tudo o que não é ser é nada e não há, nesse nível, vários tipos de nada ou vários modos de ser nada. Tudo que não é finito é infinito, tudo que não é identidade é diferença.

22 A meu ver, os parágrafos nas páginas 12/242-244 constituem uma digressão. A própria apresentação do método continua com "Ora , esse é o ponto de vista anteriormente marcado [...]".

23 Quanto à questão da negação determinada cf. H. RÖTTGES. Der Begriff der Methode in der Philosophie Hegels. Meisenheim a.G., 1976, 54-62; V. HöSLE, Hegels System. Der Idealismus der Subjektivität und das Problem der Intersubjektivität. Hamburg, 1988, 194 f.; CH. IBER, Metaphysik absoluter Relationalität. Eine Studie zu den beiden ersten Kapiteln von Hegels Wesenslogik. Berlim; Nova Iorque, 1990, 221-223 
sariamente se apresenta de outra forma, uma vez abandonada a condição de "ciência absoluta" hegeliana. Essa mudança pode chegar ao ponto do determinar, superficialmente considerado, não se apresentar mais de forma alguma como processo e não se apresentar mais de forma dialética. Mas para tal fim carece investir o que excede a capacidade produtiva do pensamento puro: carece introduzir pressupostos e suposições adicionais ou efetuar abstrações. Tais suposições adicionais são e.g. tempo e espaço, que possibilitam uma diversidade nãorelacional e nela um ser-determinado ocasional, contingente; ou e.g. a diferença entre sujeito e objeto, que possibilita, entre outros, deslocar a forma temporal ou a atuosidade do determinar apenas para o sujeito.

Como o imediato no seu negativo, i.é. no Segundo do procedimento, está conservado, agora está dado outra vez uma instância concreta feita de mediação e imediato. Só que aquela parte, que no inicial Primeiro era dada só como deficiência e dever, agora existe como realizada (12/245). Ela faz parte então da determinação que constitui o dado e não é somente implicitamente "co-dado" como exigência. A mediação agora é posta, ela é dada, assim como o imediato. Então a mediação está coordenada e justaposta ao imediato na coisa agora dada. Mas então essa coordenação ou justaposição do positivo e do seu negativo apresenta outra vez um dever ou uma exigência, que espontaneamente devemos reconhecer como lógico - e que em geral estamos ainda mais dispostos a reconhecer do que a exigência da mediação do imediato. É essa a exigência da contradição: que a unidade não-diferenciada de instâncias mutualmente excludentes não pode ser ou não pode ser verdadeira (ibid.). Mas no primeiro Negativo é dado exatamente este fato: o ser aí - igualmente vigente - de um lado do imediato e do outro do seu Negativo - sem que haja uma diferenciação adicional hierarquicamente superior entre eles. ${ }^{24}$

Eis o ponto no qual entra a forma do juízo no proceder do pensamento puro embora ainda não explicitamente. O que está dado agora são duas determinações em uma unidade de identificação - e é exatamente isso, que o juízo representa de um ponto de vista formal. Assim a forma, na qual nós articulamos a situação do

Cf. CH. IBER. Subjektivität, Vernunft und ihre Kritik. Prager Vorlesungen über den Deutschen Idealismus, Frankfurt a.M., 1999, 178 f.; ou também K. DüsInG. Das Problem der Subjektivität in Hegels Logik. Systematische und entwicklungsgeschichtliche Untersuchungen zum Prinzip des Idealismus und zur Dialektik (Hegel-Studien, Beiheft 15). Bonn, 1976, 180; só com o Segundo, o negativo do Primeiro, a contradição aparece, só agora ela está posta no proceder do método. Assim talvez não esteja bem correto que E. LUFT já iguale a deficiência do Primeiro à contradição. Mais importante que essa diferença, porém, é o fato de que a contradição no Segundo não é outra coisa senão a aparência ou o ser-posto daquela mesma negatividade que já estava dada na deficiência (só que nela ainda não na forma da contradição). Assim a aparência da contradição no Segundo não é a aparência de uma segunda contradição - depois de uma primeira na deficiência -, mas o caráter contraditório da própria deficiência. - Só que a deficiência descreve exatamente essa compreensão da negatividade, na qual o caráter de contradição em si do deficiente não está posto, não está eme-para-si. E como a forma dos pensamentos - ou a determinação do nível de compreensão - é essencial no proceder da CL, a diferença entre deficiência (como contradição somente em si, não posta) e contradição (como contradição no seu conceito próprio) é importante. 
pensamento puro ao patamar da contradição, é um juízo, um juízo contraditório. ${ }^{25}$ "Ser e Nada são a mesma coisa" ou mais simples: "Ser é Nada".

Quanto à discussão da contradição em Hegel, só quero mencionar aqui que a diferença da mesma contra o entendimento geral da contradição não consiste no próprio conceito da contradição, ${ }^{26}$ mas na localização dela numa lógica de tipo "dinâmico" ou "atuoso". O contraditório continua sendo o que necessariamente não pode ser. Mas como a lógica agora é dinâmica, e como assim algo pode mudar na esfera do lógico, o que logicamente não pode ser não precisa ser banido do âmbito do lógico e com isso do real. Pode ser remediado dentro do mesmo. A necessidade lógica é uma necessidade rigorosa, e assim o contraditório mesmo na lógica hegeliana não pode "subsistir". Tão logo aparece, já deve sucumbir com necessidade lógica - sem que lhe seja dado o direito à permanência na esfera do lógico, por mínimo que seja. Mas o contraditório de fato é na transição, no próprio sucumbir, no puro devir imediato. Mesmo assim, poderíamos formular: a contradição não "é dada" em nenhum lugar do espaço lógico, pois seu lugar é o ponto sem extensão nenhuma, o ponto de inflexão no processo lógico do determinar $(12 / 246){ }^{27}$

A necessidade da contradição então exige que o que é dado com o segundo, i.e. com o Negativo, seja imediatamente negado - o contraditório não pode existir ou não pode ser verdadeiro. Mas agora com a negação no pensamento puro, como acabamos de explicar, o negado não é simplesmente excluído do espaço do lógico. A conclusão não é: "o contraditório não pode existir, então nunca existiu e temos de começar tudo de novo, num lugar inteiramente diferente." A negação exigida pela contradição é efetuada no que é dado como negação determinada. Isto é, o próprio contraditório agora será negado de modo determinado, quer dizer, ele vai ser negado de maneira, que ele mesmo permaneça conservado no seu negativo (ibid.).

Mas num primeiro momento temos de analisar o que é negado. No primeiro caso foi negado algo imediato. Mas agora não estamos mais diante de algo imediato, mas diante de algo mediato, conseqüentemente diante da própria mediação anteriormente efetuada. Essa mediação, agora dada, consistiu apenas na pura e simples negação determinada. A mediação dada agora é a simples exclusão do imediato pelo primeiro negativo (e vice-versa). Nega-se agora essa negação, essa simples exclusão ${ }^{28}$ - e com isso se nega exatamente o que a necessidade da contradição ordena: instâncias mutualmente excludentes devem ser excluídas em uma só unidade. Assim a segunda negação não é mais negação de algo positivo, mas a negação da negação. Outra vez ela é isso de modo determinado: nega a

${ }^{25}$ Contraditório em si, i.é, analiticamente contraditório, e não contrário ou contraditório a um outro juízo, contra Cirne-Lima, op. cit. 102-120.

Aqui concordo muito com CIRNE-LIMA, cf. e.g. 156-161.

27 "Aufgehoben" no sentido de "conservada" a contradição também só é no devir como (automovimento infinito, contido no resultado.

${ }^{28}$ Cf. H.F. FULDA. Hegels Dialektik als Begriffsbewegung und Darstellungsweise, em: R.-P. Horstmann (ed.). Seminar: Dialektik in der Philosophie Hegels. Frankfurt, 1978, 124-173, 161. 
negação determinada entre os dois primeiros. A negação da exclusão necessariamente resulta no negativo dela, na inclusão dos dois. Mas como o negado está conservado na negação determinada, essa unidade não é indiferente, sem diferença, como o Primeiro Imediato era (ou parecia ser). Mas é aquela unidade, na qual os primeiros dois estão unidos num só - mas unidos exatamente no seu caráter diferenciado. É essa a identidade, na qual identidade e não-identidade estão unidos. Assim, e.g., ser e nada estão unidos e simultaneamente diferenciados no devir (cf. 247 s.), no conceito do ir do nada ao ser ou do ser ao nada.

Com este Terceiro alcançamos a famosa "Aufhebung" hegeliana. No resultado da negação do relacionamento negativo e contraditório a própria contradição é aufgehoben: as duas instâncias mutualmente excludentes não se encontram mais em uma unidade não-diferenciada, mas numa união que em si mesma tem aquela diferenciação na qual os dois primeiros não apenas estão separados um do outro, mas ao mesmo tempo relacionados um ao outro - e assim determinados um pelo outro. Assim a diferença, a negação e até a própria exclusão mútua dos dois primeiros não estão simplesmente acabadas, mas também conservadas - esse é o segundo sentido que o termo "aufheben" tem em alemão. ${ }^{29}$ Pelo Terceiro, o processo de determinação atingiu com a Aufhebung um nível mais alto do que o anterior. De um ponto de vista mais quantitativo, ele chegou a um conceito mais rico que o Primeiro, a um conceito que é superior ao imediato e ao primeiro negativo, por abarcar os dois. De um ponto de vista mais qualitativo ele chegou, de um simples e imediato entender não refletido, através de uma reflexão negativa, a uma verdadeira compreensão que compreende plenamente as determinações inerentes ao que está dado. ${ }^{30}$

Resta constatar que com a segunda negação, a negação da negação, o negar não foi simplesmente reiterado, mas, em comparação à Primeira Negação, se efetuou um novo modo de negar. Ao contrário da primeira, essa negação agora conduziu de novo a uma imediatidade, ainda que não à imediatidade indiferenciada (i.e. a "imediatidade imediata") do início. Através da negação da mediação, da suspensão da contradição, formalmente temos novamente a imediatidade - mesmo que agora ela seja concreta, diferenciada em si mesma (i.e. imediatidade mediada). Com isso, de um certo modo, um circulo se fechou (12/251, 252), mesmo que assim o início não seja simplesmente idêntico ao ponto final - como é no caso de um círculo geométrico - o que transformaria o processo lógico em movimento circular vazio. Mas o fechamento do círculo possui alguma importância, justamen-

${ }^{29}$ Assim o fato de que as duas primeiras determinações foram "falsas", como explica C. CIRNE-LiMA (op. cit. 115-119) só é um aspecto da verdade da Aufhebung; o outro é que ambas foram e continuam sendo certas, mesmo na sua aplicação a „, todas as coisas“ (e pelo menos a primeira determinação também na sua aplicação ao „Absoluto“): Num certo sentido todas as coisas de fato são ser, o Absoluto é ser - como, num certo sentido, todas as coisas de fato são nada. Só que essas frases têm sua verdade somente do ponto de vista do devir e do ser aufgehoben de "ser" e de "nada" no devir. São expressões parciais da verdade e falsas se tomadas isoladamente. Mas enquanto momentos da verdade do devir, elas têm sua própria verdade.

30 Isso foi muito bem descrito por C. CIRNE-LimA, op. cit. 125. 
te porque com ele atingimos uma conclusão do processo a partir da própria coisa mesmo que o processo da CL ultrapasse essa conclusão. ${ }^{31}$

Além disso segue que o que lá foi concluído pode ser tomado como uma singularidade - uma singularidade diferenciada e assim particularizada em si. Pelo seu ponto de partida este singular é ao mesmo tempo um universal. - Quero com isso apenas mostrar rapidamente que com o resultado do proceder se efetua a forma do conceito (12/238). Temos, portanto, de fato o que procuramos: algo estruturado em si, uma forma fechada em si, um singular particular, que seja o universal do determinar e do compreender conceitual. Não temos somente um axioma geral, como e.g. o principio omnis determinatio est negatio ou a sentença da não-contradição ou da identidade. Temos algo que com boas razões, ainda que num entendimento modificado, podemos denominar método: um modo estruturado de efetuar o determinar.

Agora, com a imediatidade formal do resultado não só está completado o ciclo, mas também está dada a possibilidade de um novo procedimento metódico pois outra vez está dada a imediatidade (12/248). Mas como nessa imediatidade a plena concreção do procedimento anterior está conservada, esse procedimento dar-se-á de outra forma que o anterior - pois a negação determinada, na qual ele se efetua, sempre recolhe o que está dado. Com isso, então, o procedimento a seguir não somente resulta em conteúdos, determinações e conceitos diferentes do anterior. O próprio modo do seu proceder, a concreção do método geral dar-seá também de outra forma. Por isso o método absoluto, apesar de toda monotonia formal, não é um simples padrão de malha. ${ }^{32}$ Da mesma forma o enriquecimento do conceito, a modificação do método não ocorrem no acréscimo de algo novo, vindo de fora, mas de modo que o que já está dado sucessivamente é incorporado ao proceder e com isso ao pensar, ao compreender.

Queremos ilustrar isso apenas brevemente com a diferenciação geral do método nos três livros da Lógica: na Lógica do Ser o procedimento se efetua sabidamente na transição: $:^{33}$ o método faz valer sua necessidade de imediato, embora a mesma ainda não tenha sido compreendida. Corresponde a isso que no movimento do pensar a conexão interna do próprio movimento ainda não é compreendida.

${ }^{31}$ Por isso não convém substituir a imagem do círculo (como algo fechado em si) pela espiral (aberta na terceira dimensão), mesmo que assim se tente resgatar o "aspecto do ganho adicional". Com isso se perde a idéia significativa e decisiva da metáfora do círculo no contexto de Hegel - cuja força explicativa, como a de toda metáfora na discussão do absoluto, é limitada.

32 Cf. D. WANDSCHNEIDER, Grundzüge einer Theorie der Dialektik. Rekonstruktion und Revision dialektischer Kategorienentwicklung in Hegels, Wissenschaft der Logik'. Stuttgart, 1995, 186.

33 Cf. P. SCHÄFER, Die Dialektik und ihre besonderen Formen in Hegels Logik. Entwicklungsgeschichtliche und systematische Untersuchungen (Hegel-Studien, Beiheft 45). Hamburg, 2001, 295-228. SCHÄFER, porém, não quer reduzir a explicação do método (seguindo a sua própria sistemática, como foi aqui demonstrado) a uma forma unitária do método (cf. 292); em vez disso, vê neles diferentes tipos fundamentais de dialética. Assim ele não logra compreender adequadamente nem a sua unidade nem a sua diferenciação progressiva do sistema da Lógica, até a peculiaridade de cada passo dialético individual. Muito menos ainda ele pode compreender a necessidade do procedimento - pois essa precisaria consistir na compreensão de uma dialética que intermediasse entre, logo abrangesse todos os "tipos de dialética". 
Por isso os momentos do método se apresentam como uma sucessão procedendo de determinações do pensar que se revezam entre si. Na Lógica da Essência já está incorporado ao pensar que a negação determinada só revela - i. é, só põe - o que já estava dado no imediato; e por isso o imediato por sua vez nem era imediato de todo, mas só parecia sê-lo. Assim o modo de proceder na Lógica da Essência é a reflexão, que de certa maneira se move para trás. Na Lógica do Conceito, finalmente, o método completo é incorporado ao próprio procedimento metodológico do pensar (mesmo que, de início, ainda só em si e não por si - como também o próprio conceito). Assim se compreende por um lado, que não ocorrem revezamento nem transição, mas que o pensamento permanece na sua coisa, apesar de todo o proceder. Por outro lado compreende-se que o procedimento do pensar não apenas abole negativamente uma aparência, mas que, através dessa mesma ação, a própria coisa se desenvolve efetivamente nela mesma, sendo portanto positiva, construtiva e sintética no seu resultado. Para caracterizar tal proceder na própria coisa, sem jamais abandoná-la, serve o conceito do desenvolvimento.

Com a seqüência de transição, de reflexão e de desenvolvimento só pretendi mostrar exemplificativamente como o método se pode, por si mesmo, diferenciar e determinar mais ampla e abrangemente, sem com isso perder a sua monotonia formal ou simplicidade e universalidade - e sem questionar o ganho que a contemplação dessa forma universal traz: a compreensão das possibilidades e necessidades universais do determinar. Nos pormenores, o método absoluto naturalmente se realiza em cada um de seus procedimentos de forma muito mais específica - simplesmente porque o seu cerne é a negação determinada, que por sua vez nunca é abstrata, mas se concretiza cada vez, tanto na sua forma como no seu conteúdo, na coisa dada.

Por isso a forma geral do método, abstraída das formas que ela assume nos procedimentos individuais do determinar, efetivamente não explica muito. Ela indica que a determinação tem a forma da efetivação ou se estrutura assimetricamente; e que essa forma de efetivação está diferenciada em si mesmo, contendo duas negações posicionadas assimetricamente uma com relação à outra. Ocorre que essa forma do método já é suficientemente substanciosa para fundamentar teses filosoficamente exigentes. Uma delas afirma que nada, em que a forma do método não esteja realizada ou posta integralmente, pode ser algo autodeterminado, subsistente em si, autônomo e definitivo. Na terminologia de Hegel isso significa: não há determinação abaixo do nível do "conceito" enquanto estrutura efetuada do método. Toda e qualquer determinação aparentemente mais simples deriva do conceito. E como todo e qualquer real é determinado, o conceito é a forma universal do real - daí o idealismo objetivo.

A outra tese de Hegel afirma que a forma do método se enche por si mesma de conteúdo, quando começamos sem qualquer pressuposto, seguindo total e exclusivamente a dinâmica imanente ao método. De um lado, ela é o método universal do determinar e do conhecer - e assim de qualquer determinar e conhecer; por outro lado, no seu sentido eminente, ela é o método de somente um determinar e conhecer, nada gratuito, a saber do determinar absoluto na Ciência da 
Lógica - e a seguir do resto do sistema filosófico hegeliano. E isso porque num sentido fundamental e absoluto antes de tudo só existe esse determinar e conhecer, esse compreender da Lógica. As demais formas do determinar e do conhecer só resultam das possibilidades postas à disposição pela Lógica - adicionadas da possibilidade do acaso real e da multiplicidade indiferente, dadas pelo espaço e tempo (por sua vez imediatamente resultantes do livre demitir-se da idéia absoluta no fim da Lógica).

\section{Crítica - o "Aufbruch" ("iniciar-se”)}

Como já foi indicado, quero apoiar a pretensão de Hegel de que não podemos retroceder para aquém do seu método dialético e de que ele é universal no sentido exposto. Quero objetar, porém, que apesar disso ou exatamente por isso, não é possível derivar dele uma determinação absoluta nem uma necessidade absoluta, mas que o procedimento dialético - enquanto origem do determinar tem por peculiaridade um momento de acaso (Zufall). Procurei desenvolver em outra publicação diversos caminhos argumentativos para provar essa tese. ${ }^{34}$ Aqui só quero mencionar o mais imediatamente compreensível entre deles. ${ }^{35}$

A forma do método é, por assim dizer, ambivalente. É verdade que primeiro parece que o resultado do procedimento seja inequivocamente superior ao Primeiro Imediato e à negação simples - e isso não por causa de critérios externos, mas porque ambos são conservados [aufgehoben] nele. O resultado é unidade de imediatidade e mediação, identidade de identidade e não-identidade. Mas há efetivamente um pendant equivalente a essa Aufhebung. Na sua construção abstrata ele ainda se afigura banal e de reduzido teor explicativo: é a diferenciação de imediatidade e mediação, a não-identidade de identidade e não-identidade. Ora, esse pendant equivalente à Aufhebung não é só uma construção teórica, mas está de fato concretamente dado no procedimento dialético, i. é, na totalidade do procedimento antes da Aufhebung, quer dizer, na totalidade do primeiro passo metodológico. Contrastando-o à Aufhebung, poderíamos denominar "iniciar-se" esse passo na sua totalidade. Em alemão isso é "der Aufbruch". À semelhança do termo "Aufhebung", "Aufbruch" tem vários significados, para os quais a língua portuguesa não oferece uma única palavra. Quero usar três desses matizes para caracterizar melhor o "iniciar-se". Em primeiro lugar, Aufbruch, compreendido como "iniciar-se", tem o sentido de começar: na totalidade do Imediato e do Mediato na sua diferenciação originária, principia a dialética; em segundo lugar, Aufbruch tem o sentido de romper, de quebrar ou de arrombar (como se faz com uma fechadura e.g.): no "iniciar-se" a primeira unidade e simplicidade é rompida (é bom lembrar aqui, que mesmo para Hegel essa unidade primeira pode ser aquela de uma $A u-$ fhebung - quando o procedimento começa com o resultado de um procedimento metódico anterior. Assim o Aufbruch automaticamente tem o poder de romper

4 Cf. K. UTZ, op. cit.

35 Ibid., 180-188. 
não só alguma unidade imediata, mas exatamente aquela da Aufhebung. Então o "iniciar-se" tem o poder de por em questão a Aufhebung, lhe é eqüipolente.) Em terceiro lugar, o termo Aufbruch tem também o sentido de abrir-se e assim revelar algo, de mostrar algo novo ou dar luz a uma realidade nova (como e.g. faz o botão de uma flor).

Até aqui tudo ainda é mais ou menos compatível com a CL, pois Hegel explica tal coisa com o judicar, o "Ur-teilen". A palavra alemã tem também o sentido de "dividir originariamente", tendo sido usada nesse sentido já antes por Hölderlin e Fichte. Mas deve-se notar, que o Aufbruch ou o Ur-teilen agora é um fato, que a Aufhebung não pode mais interiorizar e do qual ela não pode mais dar conta. Ela só suspende e conserva [aufhebt] o imediato e a mediação - a saber, na sua unidade. Não suspende e conserva [aufhebt] o seu caráter distinto ou a sua nãoidentidade, mas simplesmente nega-a. Mas nessa relação de simples negatividade a Aufhebung não é mais superior ao Aufbruch. ${ }^{36}$

Disso resultam duas coisas: a direção do procedimento dialético não está mais garantida. Essa necessidade, que a Aufhebung seja a conclusão do procedimento, superior a todo anterior, não é mais inerente à forma do método. Certamente ainda lhe é inerente que em todo iniciar-se figura uma necessidade da Aufhebung; inversamente há em toda e qualquer Aufhebung uma possibilidade do iniciar-se. E essa vez a possibilidade (do iniciar-se) é igualmente ameaçadora para a Aufhebung, assim como a necessidade (da Aufhebung) é ameaçadora para o iniciar-se, pois este não é determinável nem previsível como possibilidade, a partir da Aufhebung.

Em segundo lugar, resulta algo até mais fundamental ainda: a assimetria no proceder provou-se como exigência da lógica do determinar. Enquanto a forma metodológica de Hegel permanece incontestada, a assimetria é incorporada [aufgehoben] como necessidade no/ao próprio método, pois o método apresenta exatamente aquela forma originária e básica de assimetria dinâmica, que ao mesmo tempo é formalmente garantida - a saber, na superioridade do resultado sobre o início. Mas se essa superioridade desaparece, a assimetria não pode desaparecer, pois sua necessidade originária resulta da exigência originária da negação, e essa não pode desaparecer. Mas a assimetria agora não pode mais ser recuperada como resultado. Permanece originária e deve ser aceita como tal, como princípio próprio.

Ocorre que a assimetria na sua concreção consistia exatamente nisso, que a mediação tem de ser principiada. Essa principiação, este começar originário tornase agora o inderivável e irrecuperável, a instância do próprio procedimento dialético, aquém da qual não se pode ir. O advento do movimento dialético não pode ser recuperado na possibilidade e na necessidade da dialética, porque constitui em cada caso a sua realidade.

${ }^{36}$ De resto, uma superação (Aufhebung) adicional dessa simples relação negativa não resolveria o problema, pois agora se trata exatamente da Aufhebung e do Aufbruch próprios, do que resulta a iteração do questionamento em cada patamar sucessivo de reflexão. 
Neste sentido todo o advento do procedimento dialético é acaso. É o acaso, do qual precisamos partir em todo determinar, quando assumimos, como aqui sugerido, que o método dialético, como Hegel o indicou, de fato é a origem intransponível [unhintergehbar] de todo determinar. Mas ele é também o acaso para o qual temos de nos manter abertos em todo determinar, porque nele a necessidade da Aufhebung e a possibilidade do Aufbruch não são ponderáveis entre si. Assim a pretensão do método "absoluto" hegeliano continua vigente - mesmo que talvez a palavra "absoluto", depois das modificações explicadas, possa conduzir a mal-entendidos. Até a Ciência da Lógica mantém sua legitimação, sem prejuízo de todos os pormenores criticáveis. Mas a sua verdade se torna verdade unilateral, parcial: passa a ser a verdade da necessidade contra a verdade da possibilidade, a verdade da Aufhebung contra a verdade do Aufbruch ou originar-se. A totalidade da verdade, porém, deveria ser buscada num lugar, para o qual a palavra acaso (Zufall) só é a indicação do local, o topos: no advento originário, não derivado e não encaminhado, da dialética. ${ }^{37}$

\section{O acaso}

O acaso é um acontecer, por meio do qual nasce algo novo, algo não totalmente condicionado por uma situação anterior e por regras gerais do desenvolvimento e procedimento. Assim o resultado não está inteiramente redutível à origem (sendo, portanto, algo incondicionado). O acaso representa em si a transição de uma determinação a outra, sem que a própria transição seja totalmente determinada e, nesse sentido, sem que o processo seja determinístico. Assim o acaso é a transição do determinado ao indeterminado, do condicionado ao incondicionado e vice-versa. Ele realiza exatamente aquela "mediação complexa imediata", cuja explicação é tão difícil, pois cada tentativa de explicação resulta ou em indeterminidade ou em contradições.

Ao mesmo tempo o acaso não é totalmente indeterminado. Não é o indeterminado e o incondicionado. O resultado dele é determinação e não $\operatorname{caos}^{38} \mathrm{E}$ o

${ }^{37}$ Seja admitida ao menos em uma nota a imodéstia da posição filosófica aqui esboçada: Se a filosofia transcendental de Kant é a „virada copernicana“ da filosofia, então a teoria, que tenta provar a intransponibilidade [Unhintergehbarkeit] do acaso - no sentido de sua indeterminabilidade como no de sua infundamentabilidade - em todo determinar e fundar/demonstrar, e que conseqüentemente também explica a inderivabilidade do acontecer, deveria constituir (no caso do seu sucesso) a „virada heisenbergiana" da filosofia.

${ }^{38}$ A instalação do caos como um segundo princípio ao lado da coerência (C. CIRNE-LimA. Dialética e liberdade. Razões, fundamentos e causas. in: Veritas 43 (1998), 795-816, 815; outro problema que vejo diz respeito à simples identificação do Princípio de Caos e de Diferença - ao meu ver não soluciona o problema por duas razões: em primeiro lugar, o caos total, no qual não há nenhuma ordem, nada de determinado e nada de distinto, é uniformidade e homogenidade total: é igual à ordem e coerência abstrata absoluta. Les extrêmes se touchent como quase sempre, quando conceitos contingentes devem cumprir o papel de princípios universais. Em segundo lugar, a dualidade simples dos princípios de coerência e de caos só resulta num dualismo (como qualquer bi-principialidade ou mesmo a "igual-originariedade" heideggeriana; obviamente um tri-principialismo cf. C. Cirne-Lima 1996, 131-140, não facilita a questão -). Assim chegamos novamente à uma simetria indecisa e em última instância indeterminada de princípios opostos. Mas a mera oposição simétrica, como Hegel 
acaso não é absoluto. Ele constitui incondicionalidade e assim um tipo de caráter absoluto. Mas o resultado do acaso nunca é totalmente incondicionado pelo anterior. Sempre se insere no contexto, sempre trava na história, e só dentro das inserções faz valer uma negação delas. Se o acaso for completamente incondicionado e indeterminado por condições anteriores, ele seria o fim de qualquer determinação anterior, i. é, seria a criação de um mundo completamente novo - um mundo que não teria ligação nenhuma com o mundo anterior e nem existiria mais como passado. Mas o acaso não é isso. Ele acontece dentro do mundo, encadeia-se nas determinações anteriores. Dentro do mundo e dentro dessas ligações ele realiza algo novo. O acaso não é a ruptura total. Pelo contrário, ele constitui mediação. Ele não é o caos, ele não é o simples oposto da ordem e da necessidade; muito pelo contrário, constitui a ordem, determinação e necessidade. Ele é a mediação real e atual - e não abstrata - de imediatidade e mediatidade, da determinidade e indeterminidade, da condicionalidade e incondicionalidade. Ele é a "mediação" não é a união, não é a identidade de identidade e não-identidade, de determinidade e indeterminidade, porque nos conceitos da união e da identidade, essa mediação seria "aufgehoben" em determinação. O acaso é tanto união quanto ruptura originária, tanto identidade quanto não-identidade de identidade e não-identidade. Ele é, por assim dizer, tanto mediação quanto "não-mediação", tanto continuidade quanto descontinuidade, mas sem que se possa distinguir com exatidão entre esses dois aspectos, pois isso equivaleria à redução da mediação de indeterminidade e determinidade à determinidade: a uma relação determinada.

Esse é o conceito do acaso, a explicação aprofundante do sentido comum da palavra. A questão sempre foi: esse conceito descreve uma realidade ou descreve apenas uma impressão nossa, uma aparência? Deste o início a opinião comum foi: só nós pensamos ou temos a impressão de que algo não tenha causas completas. $\mathrm{Na}$ verdade tudo acontece plenamente, determinadamente, com plena necessidade (só Epicuro foi o primeiro que formulou o conceito de um acaso real, e só hoje em dia a opinião comum, sob a impressão da microfísica, está mudando um pouco nessa direção). A razão para isso não é somente o anseio humano pela segurança, pela ordem e pela determinação. Penso que as dificuldades teóricas acarretadas pela explicação do acaso pesaram mais: o acaso é, no fundo, inexplicável, porque ele é a transição do indeterminado ao determinado e assim do inexplicável para o explicável (assim ele é o princípio de cada ato de explicar, porque o explicar efetiva precisamente essa transição, ela faz com que algo anteriormente inexplicável

mostrou bem, não pode ser a verdade (no proceder do método essa oposição aparece no resultado da primeira negação, que em si mesma representa a contradição). Na minha opinião é válida a refutação completa de qualquer dualismo por parte de Hegel.

O problema verdadeiro e essencial, porém, é a mediação de ordem e caos, a transição entre o indeterminado e o determinado. Mas a simples instalação de um contra-princípio da ordem e da determinidade só reintroduz, não soluciona esse problema. Pelo contrário, só confirma a insolubilidade, porque se a coerência e o caos são princípios, não podem ser mais integrados um ao outro - ou ambos num acontecer abrangente, que supera exatamente esse caráter de princípio de ambos, deixando-os como momentos contingentes de uma dialética superior. 
se torne explicável - mas como princípio da explicação, a explicação não pode subsumir o acaso ao explicar).

Agora, porém, como resultado da nossa crítica a Hegel, vemos que a transição real e atual entre indeterminidade e determinidade, entre condicionalidade e incondicionalidade é necessária. Ela é logicamente necessária (e não somente por evidências empíricas, como a física moderna as fornece) - pelo menos se aceitamos a existência de uma "lógica do conceito", uma lógica do determinar ou uma lógica da semântica, como Hegel a iniciou. É necessário que haja identidade entre idendidade e não-identidade, como também não-identidade, como "Ur-Teilung", como diferenciação originária entre as duas, num só ato, num só acontecer. E para descrever esse fato, para inserir esse conceito assim descrito em nossa língua e nosso pensamento comum, uso o termo "acaso". O acaso assim é o Princípio, o princípio tanto da realidade como do espírito, da teoria e da prática. Mas ele é o princípio que nega o "princípio do princípio", que nega a própria "principialidade": não há um princípio da maneira como pensamos - um Primeiro, Universal, que rege tudo ou que pelo menos liga todas as coisas singulares entre si. Só há o acontecer originário -que nunca é completamente primacial, porque a originalidade dele sempre se insere em algo já dado. Esse acontecer principia o mundo e principia o pensar.

Como esse acontecer sempre tem também o lado da determinação, da necessidade e assim da universalidade, sempre é possível abstrair do outro lado e ficar só com um lado. Assim sempre é possível cultivar a Lógica Formal, cultivar a matemática e cultivar as ciências baseadas em ambas - e deixar fora o aspecto do irredutível e original do acaso. Mas como esse modo de pensar é constituído pela abstração, seus resultados sempre serão abstratos e assim unilaterais, nunca fornecerão a verdade em sua totalidade. E assim sempre vai faltar algo à lógica e à matemática, até internamente: não falta só a aplicação ao singular, que nunca pode ser feita com a mesma segurança e exatidão como os cálculos internos, mas sempre faltará também a completa e coerente fundamentação e determinação dos seus axiomas.

O acaso em si é dialético. A dialética é a verdade do acaso. Mas o acaso, por sua vez, é a verdade da dialética: a dialética sempre exige dialética, sempre é necessária uma união de dialética e "metadialética". Assim nunca existirá uma dialética principal, e nunca existirá um dado principal do qual a dialética possa partir. Como aqui não pode haver um processus ad infinitum nem circularidade, é preciso o realizar-se originário, o "principiar" da dialética da dialética, o iniciar da dialética na dialética. E esse acontecer originário que ao mesmo tempo se insere todo abrangente é o acaso. O acaso contém a dialética tanto no seu aspecto de Aufhebung como no de Aufbruch. E a dialética explica o acaso: explica que somente nesse realizar-se complexo de iniciar-se e superar-se pode acontecer algo, pode realizar-se algo - i. é, pode ser algo e pode-se conceber algo. O acaso fornece a possibilidade da realidade. E a dialética evidencia a necessidade do acaso. 